\title{
Violência e Saúde Coletiva: contribuições teóricas das ciências sociais à discussão sobre o desvio
}

\section{Violence and Public Health: theoretical contributions from the social sciences to the discussion about deviation}

Walter Ferreira de Oliveira

Professor Adjunto do Departamento de Saúde Pública da Universidade Federal de Santa Catarina-UFSC.

Endereço: UFSC - Depto. de Saude Publica, Centro de Ciencias da Saúde, Campus Universitário Trindade, CEP 88066-020, Florianópolis, SC, Brasil.

E-mail: walterळccs.ufsc.br

\section{Resumo}

Saúde Coletiva e Ciências Sociais e Humanas são campos reconhecidamente inseparáveis, o que se afirma por uma tradição de grupos e linhas de pesquisa em programas de pós-graduação em Saúde Coletiva. Várias dificuldades têm sido apontadas, entretanto, em inserir discussões sobre temas tradicionalmente estudados nas ciências sociais, como a violência, no campo da saúde, ao mesmo tempo em que tal discussão tem sido vista como crucial para o entendimento de determinações de condições de saúde e qualidade de vida das populações. 0 foco de discussão sobre esse fenômeno carece de aportes teóricos de outras disciplinas, como a Sociologia, cujas teorias sobre o crime e sobre o desvio da norma constituem importante marco no estudo das violências. Neste artigo, o autor examina as teorias clássicas da sociologia nesse âmbito, buscando contribuir para a ampliação da discussão no campo da Saúde Coletiva, particularmente no que concerne a uma base de pensamento sobre a promoção, a prevenção e a reabilitação de agravos, considerando-a, assim, numa perspectiva interdisciplinar e de abrangência intersetorial.

Palavras-chave: Violência; Desvio; Criminalidade; Saúde Coletiva. 


\section{Abstract}

Public Health and the Human and Social Sciences are inseparable fields of knowledge, as attested by a tradition of research groups and research lines located in Public Health post-graduate programs. Several difficulties have been pointed when discussions about various themes traditionally identified with the social sciences, as is the case of violence, are inserted in the health field. At the same time, such discussions are considered essential to the understanding of the determination of populations' health conditions and quality of life. The discussion focus regarding this phenomenon lacks theoretical contributions from other disciplines, such as Sociology, whose theories on crime and deviance constitute an important benchmark in the study of the various forms of violence. In this article, the author examines the classic sociological theories in this area, aiming to contribute to the expansion of discussion in the field of Public Health, particularly in terms of a knowledge base to be applied to health promotion, crime prevention and rehabilitation, thus considering Public Health from an interdisciplinary, intersectorial perspective.

Keywords: Violence; Deviation; Crime; Public Health.

\section{Uma Abordagem Sociológica da Violência}

As manifestações de violência constituem um fenômeno que, através dos tempos, tem afetado todas as sociedades históricas ${ }^{1}$. Hoje, a violência é fruto e resultante de estruturas, relações e contradições sociais da vida urbana e rural, é tema central da mídia nacional e internacional e objeto de atenção no mundo acadêmico, interessando particularmente à área da saúde, como demonstrado por um número de trabalhos científicos dedicados ao tema dentro do escopo da Saúde Coletiva (Minayo e Souza, 2003). No contexto dessa área de conhecimento vêm se desenvolvendo estudos e projetos de intervenção voltados para a prevenção e reabilitação de agravos devidos à violência. Nos EUA, por exemplo, criou-se um Centro de Estudos Epidemiológicos sobre a Violência na estrutura do Center for Disease Control (CDC), já na década de 1980. No Brasil, bases de dados têm confirmado a presença flagrante e a escalada da violência nas estatísticas de morbidade e mortalidade, embora se reconheça que a produção científica no Brasil ainda é pequena, comparada à produção internacional, e que as iniciativas para as intervenções sobre o fenômeno no contexto do sistema de saúde ainda carecem de maior sistematização (Minayo e Souza, 2003).

A violência, como tema de natureza complexa, é estudada a partir de diferentes abordagens, de acordo com o campo disciplinar, com as escolas de pensamento e com as funções profissionais. $\mathrm{O}$ fenômeno se insere na teia das relações sociais, sendo seu estudo indispensável para o planejamento de intervenções no contexto de um sistema de saúde universal e integrado a outras ações de desenvolvimento social e comunitário, como é o caso do SUS. Visto por esse ângulo, há um interesse especial no estudo da violência sob a ótica do pensamento sociológico. As ciências sociais, e particularmente a Sociologia, desenvolveram um olhar sobre o comportamento humano, no que concerne ao comportamento violento e fenômenos correlatos, como o crime e a delinquência, e sobre os desvios da norma em geral, que interessam ao campo da Saúde Coletiva, que busca contextualizar o com-

1 Assim consideradas as que registraram através de escritos, iconografias e outras formas, informações sobre seus modos de vida, formas de existir e de se relacionar. 
portamento humano no convívio coletivo. Para a Saúde Coletiva o ser humano é um ser social e o entendimento deste ser se dá no contexto em que ele se define, ou seja, em suas afirmações, respostas, identificações e representações como vivenciadas no território geopolítico e cultural onde exerce suas atividades vitais.

Os questionamentos da Saúde Coletiva com fins de decifrar o fenômeno da violência abrem um horizonte de discussões sobre sua natureza: É a violência condição inescapável na sociedade? É inerente à condição humana? Podem-se diminuir os índices de violência através de programas preventivos? As diferentes formas de violência têm, em essência, diferentes causas? Quais as melhores formas de abordar a violência de acordo com as diferentes fases da vida dos sujeitos? Que campos de intervenção devem ser enfatizados: o clínico, o político social, outros? Essas e outras questões mostram-se essenciais para aperfeiçoar mecanismos de intervenção e demandam conhecimento aprofundado do fenômeno. Nessa perspectiva, discutir violência implica estudá-la metodicamente e, ao mesmo tempo, verificar que chegamos, muitas vezes, nada mais que a pontos de vista, o que reitera a necessidade de aprofundar ainda mais essas discussões (Minayo e Souza, 2003).

Os estudos sobre a violência são abrangentes, complexos, constituem-se a partir de diferentes olhares disciplinares e apresentam-se freqüentemente como inconclusivos. Às vezes, revelam vieses disciplinares, apontam dificuldades metodológicas, fazem afluir sentimentos de angústia, dados os infortúnios sofridos individualmente ou coletivamente, e apontam mais zonas cinzentas que certezas no que concerne à sua genealogia. 0 desafio de desvendar, tanto quanto possível, o fenômeno, mostra-se árduo, exigindo dedicação, persistência, visão integrativa de conhecimentos e rigor metodológico, além de ousadias na formação de pontes transdisciplinares e na formulação de hipóteses que possam contribuir para o estabelecimento de teorias sobre suas causas e conseqüências em níveis individual e comunitário.

Este texto examina alguns conceitos, definições e classificações relacionados à violência, considerando a historicidade do pensamento sociológico e tecendo considerações, por contigüidade, a fenômenos como a criminalidade e a delinquência. Não nos prendemos a algumas formas de classificação da violência tradicio- nalmente mais utilizadas na Saúde Coletiva, como a violência doméstica, contra grupos específicos, pois o objetivo é exatamente inserir discussões ainda não tão exploradas nesse campo da saúde. A tradição sociológica é relacionar estes fenômenos, da violência, da criminalidade e da delinquência, ao estudo do comportamento de desvio das normas sociais. $\mathrm{O}$ autor revisa, assim, a trajetória do pensamento sociológico moderno, a partir do final do século XIX até a segunda metade do século XX, destacando-se as elaborações teóricas consolidadas nas obras de Emile Durkheim, Robert. K. Merton, Edwin Sutherland e pela escola de Chicago, considerados os alicerces das teorias sociológicas posteriores. Traz ainda alguns aportes surgidos no novo milênio, contextualizados sob a hegemonia do pensamento neoliberal e voltados para uma crítica às desigualdades produzidas por esse regime socioeconômico, vistas como fundamentais na disseminação da violência social (Minayo e Souza, 2003). 0 intento é contribuir para com as discussões sobre o tema na Saúde Coletiva, numa perspectiva interdisciplinar e considerando-se sua condição de responsável por intervenções de cunho intersetorial. Dada a extensão do campo e a variedade de conceitos, definições e classificações, não há qualquer pretensão de se ter esgotado o exame de todas as escolas de pensamento sociológico, mas apenas de expor algumas teorias que, por sua condição de marcos históricos, contribuíram para a formação de construtos sociais. Levou-se, ainda, em consideração o condicionamento da amplitude da discussão à extensão viável do texto.

\section{Violência: as implicações políticas da classificação}

Uma questão fundamental é por que definir e classificar ou, de outra maneira, a que propósitos classificações e definições podem servir? A pergunta nos alerta para o fato, já extensamente enfatizado por Freire (1989), de que há finalidades e objetivos no ato de nominar, definir e classificar. Quem define e classifica o faz orientado para determinados fins, que podem estar ligados à melhor compreensão e contextualização do fenômeno, a seu controle em nível social ou a outros objetivos. Por exemplo, as definições servem como base à elaboração, execução e avaliação de programas de intervenção, a serem realizados por forças 
policiais e militares, pelo sistema judiciário, por entidades assistenciais, associações defensoras dos direitos humanos ou sistemas de saúde. Podem, também, destinar-se à construção social de significados, sentidos e signos, que são veiculados nos diversos aparelhos de mídia. Assim, classificações e definições circunscrevem relações de poder, configurando estatutos sociais pelos quais se pautam ações e se desenham cartografias, legitimidades e proscrições. Definições moldam-se dinamicamente, em consonância com inclinações e idiossincrasias, vivenciadas e recriadas no contexto das organizações sociais, dos costumes e das tradições. As categorizações implicam, portanto, em tentativas de explicação de fenômenos e realidades, que configuram interesses, influências e embates, e contextualizam causas e conseqüências. Essas explicações são oferecidas de acordo com as orientações psicossociais, ideológicas e políticas de cada indivíduo, grupo ou sociedade, com objetivos e finalidades distintos.

Definições e classificações são, também, dispositivos lingüísticos, pois estatutos sociais são constituídos como linguagens institucionais, políticas e jurídicas. As Ciências Sociais e Humanas têm em consenso que a identidade se constitui essencialmente, do ponto de vista biosóciopsicológico, através da linguagem (Nogueira, 1978). Isso quer dizer que definições e classificações, como construções lingüísticosociais, impactam não só as maneiras de organização da sociedade, mas a própria construção das subjetividades e das relações intersubjetivas que configuram a existência humana (Wittgenstein, 1979). Assim, as definições e classificações relativas à violência, como fenômeno comportamental e relacional e como meio de produção de agravos, tomam importância central para a Saúde Coletiva. Uma infinidade de categorias de violência demanda atenção direta dos sistemas de saúde, incluindo-se aí as intervenções de emergência sobre suas conseqüências diretas. Outros desdobramentos, mais sutis, se relacionam à constituição dos sujeitos a partir das representações sociais da violência e de seu estatuto social.

As definições e classificações, ou seja, a linguagem das representações sociais do fenômeno da violência, são, portanto, fundamentais para pensar inter- pretações e intervenções que afetem a saúde das populações. 0 entendimento da violência é essencial para a construção continuada de um sistema público de saúde e seguridade social que privilegie o bem-estar e a qualidade de vida. A violência é agente contribuinte aos níveis de saúde das pessoas, grupos e populações e uma abordagem de suas definições e classificações pode proporcionar uma valiosa ferramenta para a promoção da saúde, a prevenção de agravos e a reabilitação relativa a esses agravos.

As definições e classificações que interessam à Saúde Coletiva não são somente aquelas voltadas para eventos patológicos, mas também as leituras sociológicas, antropológicas, psicológicas, ambientais e outras que constituem os diversos pontos de vista hoje incorporados ao seu campo de observação e intervenção. Partimos, assim, de definições e análises amplas da violência e fenômenos correlatos, utilizando dicionários e referenciando o campo de conhecimento da medicina psiquiátrica, por serem estes representativos fundamentais da construção social dos significados quanto a esse fenômeno. Focamos então a contribuição histórica da Sociologia para o estudo da violência e fenômenos correlatos, no sentido de estimular algumas reflexões que possam contribuir para pensar a promoção, prevenção e reabilitação da saúde das populações.

\section{Definições de Violência}

O Dicionário da Língua Portuguesa, de Aurélio Buarque de Holanda Ferreira, em sua edição de 1986, define violência como "qualidade de violento, ato violento, ato de violentar; constrangimento físico ou moral, uso da força, coação”. A 1 ${ }^{a}$. edição (1977) do Minidicionário da Língua Portuguesa, do mesmo autor, relaciona o ato violento com, entre outros, "agir com ímpeto, agitação, tumultuoso, irascível, intenso, veemente, em que se faz uso de força bruta, contrário ao direito, à justiça”. Exibe ainda o verbete "violentar", relacionado a "violar, forçar, arrombar"; e o verbete "violar", relacionado a, entre outros, "infringir, transgredir, estuprar, profanar, poluir, divulgar e revelar”. Já o New Lexicon Webster's Dictionary of the English Language, Encyclopedic Edition (1989), define violência como 
“o uso de força física com sentido de causar dano ou injúria; força ou energia natural intensa; uso abusivo de força; paixão; fúria; distorção de significado (distortion of meaning); profanação, violação (desecration)"; e coloca, ainda, como ato violento, "ofender o senso de justiça de outrem". ${ }^{2}$ Tais definições estabelecem uma amplitude terminológica, colocando o problema em diferentes níveis e contextualizando-o em diversos campos de conhecimento e de intervenção social. Já o Dicionário de Filosofia, de Abbagnano (2000, p. 1002-1003), particulariza dois enfoques, definindo violência como "ação contrária à ordem ou à disposição da natureza" e como "ação contrária à ordem moral, jurídica ou política”, permitindo um alinhamento com as teorias sociológicas do desvio, que serão examinadas abaixo.

As definições colocadas acima são corroboradas na $7^{\text {a }}$. edição do Compêndio de Psiquiatria, de Kaplan e colaboradores (1997, p. 17o), que coloca no mesmo patamar os termos violência e agressão, esta definida como "comportamento direcionado ao objetivo de ferir outra pessoa... [e] implica a intenção de prejudicar, que deve ser inferida de eventos que precedem ou seguem os atos agressivos." o Compêndio de Psiquiatria enfatiza que atos agressivos são perpetrados tanto por pessoas com transtornos mentais como por pessoas que não têm nenhum diagnóstico psiquiátrico e que esses atos são, em sua maioria, dirigidos principalmente a pessoas conhecidas, geralmente membros da família (com exceção de agressões indiscriminadas, cometidas por adolescentes); são favorecidos pela descompensação psicológica, às vezes auxiliada pela ingestão de grandes quantidades de álcool; e distribuídos diferentemente, de acordo com o tipo de violência, entre os gêneros: homens e mulheres apresentam comportamento agressivo de mesma intensidade nos atos de violência doméstica enquanto os homens apresentam maior presença nas estatísticas de violência no que se refere a homicídios, espancamentos, ataques com armas e estupros.

Do ponto de vista estatístico, o Compêndio de Psiquiatria, cuja edição citada ainda serve como importante texto didático para os cursos da área da saúde mental no Brasil, apresenta dados do FBI, mostrando que nos EUA foram cometidos, em 1992, 1.932.274 crimes violentos (assassinato, estupro, roubo com violência e assalto com agressão), contabilizando 109.062 estupros e 23.76o homicídios e destacando que os índices de crimes violentos são mais altos nas grandes áreas metropolitanas e mais baixos nas áreas rurais. Em análises mais recentes, têm sido confirmadas as tendências apontadas por Kaplan e seus colegas, e tem chamado atenção a escalada de violência vivida nos EUA e particularmente o protagonismo dos jovens como perpetradores e vítimas de violência naquele país (CDC, 2008). Outros autores têm sugerido que, principalmente nas grandes cidades, entre as causas do comportamento violento, encontram-se alguns determinantes ambientais. Nesse sentido, discorrem sobre o possível efeito das partículas de chumbo no desencadeamento de comportamento violento entre jovens e Kaplan e colaboradores (1997) destacam os efeitos da poluição do ar, do ruído excessivo e da superpopulação. No Brasil, vale ressaltar, a superpopulação no sistema carcerário tem sido objeto de atenção da grande mídia, que mostra, diariamente, os horrores da violência extrema que se instaura nas cadeias, atribuídos ao estresse causado pela superpopulação.

Esta breve exposição reafirma algumas questões sobre a natureza da violência, particularmente sua inerência à condição humana; sobre a preponderância de fatores biológicos ou ecológicos na determinação do comportamento agressivo; sobre os modelos de organização socioeconômicos e sua influência sobre os padrões de violência; sobre a possibilidade ou impossibilidade de uma sociedade sem violência; e outras. Algumas teorias oferecidas pelas ciências sociais, particularmente pela Sociologia, contribuem para explorar algumas dessas questões.

\section{Teorias Sociológicas do Desvio e da Delinquência ${ }^{3}$}

A Sociologia européia e dos EUA têm se interessado pelas manifestações do fenômeno da violência principalmente a partir da ótica do desvio da norma e da delinquência. É a partir dessa ótica que esta ciência tem oferecido suas contribuições teóricas sobre o comportamento

3 Nesta análise lançamos mão, principalmente, das coletâneas de Adler e Adler (1994), Rubington e Weinberg (1968) e Traub e Little (1994). 
agressivo, principalmente nas sociedades urbanas.

Teorias sobre o desvio da normalidade remontam à Antigüidade clássica. Nisbet (apud Rubington e Weinberg, 1968) levanta a hipótese de Platão ter escrito $A$ República para explicar o comportamento aberrante de muitos atenienses, o que ele interpretava como sintomas de uma patologia social. Já Aristóteles chegava a basear sua análise do comportamento natural em uma distinção fundamental entre movimento segundo a natureza, que leva os elementos harmonicamente a seu lugar; e movimento por violência, que afasta os elementos de seus lugares, caracterizando uma desarmonia (Abbagnano, 200o, p. 1002) Desde essa época e até os filósofos modernos, estruturou-se a idéia de investigar as relações entre a delinquência e a ordem e a desordem social, o controle do comportamento social, a desobediência civil e o conformismo. A Sociologia tomou essas investigações como um de seus carros chefe, contribuindo para as representações sociais sobre o tema e tornando-se responsável por muito do que se pensa, hoje, sobre esses assuntos.

Emile Durkheim, sociólogo francês (1858-1917) conhecido por suas investigações sobre o suicídio, exerceu grande influência no pensamento ocidental no que concerne à natureza da delinquência. Seu interesse pelo assunto converge com seus escritos sobre a Ética e a Moralidade. Para Durkheim, todos os fenômenos humanos estão interligados e representados nas relações sociais. Como corolário, ele não admite que se possa conceber uma ética abstrata, desvinculada dos outros fenômenos sociais. Assume, então, a existência de uma relação particular da ética com a economia, a política, a estatística e a elaboração das leis científicas, propondo que o modelo de desenvolvimento econômico adotado pela sociedade traduz-se em prescrições, com função de moldar os desejos e aspirações dos indivíduos, com a finalidade de cooptá-los à adoção das maneiras de viver compatíveis com o modelo econômico vigente. Alerta que isso pode se traduzir em desigualdades, injustiça e exploração, legitimadas por códigos legais e estatutos sociais. E que pode, também, suscitar reações por parte da sociedade, quando esta reconhece no processo uma perversão. Essas reações que se manifestam tanto no terreno das idéias como no das ações, inclusive em atos desviantes, transgressores ou violentos, que podem ser criminalizados na ótica do status quo (Durkheim, 1972, p. 89-107).
Foi Durkheim quem primeiro sugeriu que as taxas de criminalidade só poderiam ser devidamente estudadas tomando-se em consideração as normas sociais e a ruptura dessas normas que se operam na sociedade. Postulou que o crime é, assim, necessário para a sobrevivência da sociedade, isto é, tem uma função social - daí a referência a esta lógica como funcionalista. Para Durkheim, a transgressão da norma funciona para o avanço da sociedade, já que nem sempre a norma corresponde a um fato natural, ou seja, nem sempre define indiscutivelmente o que é melhor para a sociedade, mas pode estar refletindo o que é melhor para determinados grupos sociais. A transgressão pode ser o comportamento mais adequado para superar as desigualdades e injustiças causadas pelas normas ditadas pelos poderes estabelecidos, desafiando o ordenamento que assim se constitui. Um de seus principais legados foi a proposição da delinquência, neste nível de superação, como parte da natureza humana, um atributo natural que exerce uma função na coletividade social. Negava, assim, a idéia do comportamento desviante como uma patologia, que deve ser "curada”, assertiva que tem implicações diretas para o trabalho dos profissionais de saúde.

O impacto de Durkheim só chegou ao continente americano pouco antes da metade do século XX. Antes de sua influência ser sentida na sociologia americana, a chamada escola de Chicago, composta principalmente por sociólogos da Universidade de Chicago, já havia desenvolvido suas próprias idéias, priorizando a teoria da desorganização social. Esta defende que as taxas de delinquência encontradas naquela cidade mostravam-se maiores onde havia, comparativamente, alto teor de desorganização social. Argumentavam, a partir daí, que a delinquência era um problema de patologia social. Essa idéia também tem implicações diretas para o trabalho em Saúde Coletiva.

A teoria da desorganização social explica a delinquência como conseqüência de fenômenos como imigração, industrialização e crescimento urbano, que tendem a romper ou inibir padrões estáveis, bem organizados, de vida social, orientados por regras de conduta aceitas nas comunidades. A desintegração das regras em períodos de rápida transformação urbana leva ao enfraquecimento ou ao desaparecimento dos padrões de regulação. Essa tendência à desorganização social, em áreas onde aparecem, ao mesmo tempo, 
outros problemas, como populações transitórias, especulação imobiliária e altas taxas de morbidade, propicia um fértil território para as patologias sociais.

0 resultado da combinação da teoria funcionalista com a da desorganização social foi a convergência para a teoria da anomia, também enunciada inicialmente por Durkheim e defendida, entre outros, por Robert K. Merton. Durkheim, da mesma forma que a escola de Chicago, defendia que, à medida que as regras sociais, numa sociedade complexa, se enfraquecem ou se deterioram e perdem sua consensualidade, seus membros se sentem menos compelidos a respeitá-las. Nessa situação, que Durkheim conceituou como anomia, há tendência de aumento inclusive nas taxas de delinquência e suicídio. Pode-se considerar que, tanto o que Durkheim chamava de anomia quanto o que a escola de Chicago chamava de desorganização social, levam à hipótese, que será examinada adiante, de que as taxas aumentadas de delinquência resultam de condições estruturais da sociedade, que também interessam à Saúde Coletiva, sobretudo no que concerne à formulação de políticas públicas de saúde de natureza intersetorial.

Merton era particularmente enfático em sua análise da delinquência como fenômeno conseqüente à anomia. Postulava que quando praticamente todas as pessoas em uma sociedade são ensinadas a buscar objetivos culturalmente prescritos, como sucesso profissional e dinheiro, que nem todos podem obter, já que nem todos têm acesso aos meios legítimos que garantem esses objetivos, o resultado será um alto índice de delinquência e violência. Merton previa que a delinquência, graças a esta dinâmica, seria encontrada nas classes socioeconômicas mais baixas, já que seus membros são compelidos a buscar os objetivos prescritos, mas não lhes são dados os meios legítimos para sua obtenção.

Edwin H. Sutherland contribuiu à explicação sociológica do desvio e da delinquência, questionando dois pontos importantes na teoria da anomia. Primeiro, como explicar o crime fora das classes socioeconômicas inferiores (por exemplo, o chamado crime de colarinho branco)? Os crimes cometidos pelas classes média e rica não seriam explicáveis pela falta de acesso aos meios para obtenção de sucesso profissional e financeiro. Com base nesse questionamento, levantou uma questão metodológica. Defendia que uma teoria deve enquadrar todos os fenômenos que ela pretende explicar. Se houver um caso não explicável pela teoria, o caso deve ser classificado de outra forma ou a teoria tem que ser modificada. A partir da não explicação do crime nas classes econômicas mais favorecidas, deixou em suspeição as teorias da anomia e a da desorganização social, já que estas não explicavam todos os casos. Propôs então sua teoria da associação diferencial, em que os indivíduos aprendem a respeitar as normas sociais ou a delinqüir, a partir de suas relações com outros indivíduos. A condição primordial para o comportamento criminoso e / ou violento, nesta perspectiva, é estar em associação, ou seja, em companhia, de outros que sejam favoráveis à violação das normas. A seu ver esta teoria explica melhor as motivações e o comportamento criminoso e violento independente da classe social. Tira assim o foco das taxas de delinquência em circunstâncias específicas e volta-se para os aspectos interativos (aprendizagem por associação), racionalizações e mecanismos de tomada de decisão que condicionam o processo de tornar-se desviante.

Mas os sociólogos continuavam a se defrontar com uma questão central: por que uns, sob mesmas circunstâncias, às vezes com o mesmo universo de interações, com os mesmos tipos de associação, ou seja, nas mesmas companhias, tornam-se desviantes, delinqüentes ou criminosos, e outros não? Surgiu então a teoria do controle, explicando que as normas sociais, em si mesmas, são responsáveis pela diferenciação: muito mais indivíduos são tentados a desobedecer às normas, mas os mecanismos de controle e punição fazem com que uma maioria resolva não satisfazer seus impulsos. Essa explicação nos faz apenas redefinir a questão: por que uns controlam seus impulsos e outros não? A teoria do controle, faça-se um parênteses, nos fornece um insight sobre a natureza humana, ao explicitar que uma grande maioria, não fosse inibida pelos controles, seria, efetivamente, delinqüente. Em outras palavras, a diferença entre os que perpetram atos agressivos e os que se controlam não estaria na natureza de seus impulsos, mas no controle perante a possibilidade da punição. Essa questão é de grande valor para a Saúde Coletiva, particularmente no que concerne às intervenções sobre grupos e comunidades, bem como nas políticas sociais de coerção, que os sistemas de saúde adotam como base de prevenção. 
A explicação da delinquência pelos teóricos do controle reside, em parte, na socialização inadequada. A questão foca-se, aí, no controle interno. 0 indivíduo que controla seus impulsos tem controle interno forte e esta força vem de alguns fatores, entre eles, a possibilidade de atingir seus objetivos na vida e os riscos que o sujeito se permite de acordo com a medida desta possibilidade; e, por outro lado, o nível de integração social, evidenciado pelo vínculo com outras pessoas e com a estrutura normativa da sociedade. A delinquência aparece onde esses mecanismos, que condicionam o controle interno, sofrem ruptura, deterioração ou onde não foram devidamente fomentados.

A sociologia foi, assim, incorporando essas teorias e voltou-se, eventualmente, para explicações que combinassem os aspectos interativos e as relações dos indivíduos com os estatutos construídos pelas instituições que se voltam para o controle comportamental. Uma das tendências teóricas importantes, nesse sentido, é a de considerar as conseqüências da rotulação ou estigmatização dos indivíduos. Traub e Little (1994) apresentam esta teoria através de uma questão central: O que acontece com uma pessoa que é oficialmente rotulada como delinqüente ou criminosa? E assim respondem: Essa pessoa pode passar a se ver principalmente como um proscrito social e reforçar comportamentos de acordo com esse rótulo. Segundo, ela pode ser discriminada, graças a essa reputação, sendo-lhe negadas oportunidades de assumir papéis sociais destinados somente aos não delinqüentes. Em conseqüência dos anteriores, pode buscar conforto moral junto a outros também assim rotulados. Assim se formam, de acordo com os autores, as subculturas desviantes, das quais as gangues são um protótipo nas sociedades urbanas contemporâneas. Traub e Little (1994), acompanhando as proposições já colocadas por Goffman (1965), responsabilizam os agentes de controle da sociedade pela estigmatização dos desviantes, potencializando a construção de suas autoimagens como tal, ao invés de ajudá-los a encontrar meios de melhor conviver com as normas sociais. Dessa forma, o estigma funciona como risco para si e para outros, através de uma possível potencialização do isolamento e da conseqüente ruptura com uma ética baseada no respeito ao outro e à vida.

A teoria da estigmatização deslocou o foco do desviante, para aqueles a quem a sociedade dá o poder de rotular, diagnosticar e estigmatizar. Os que detêm o poder definem quais ações são criminosas ou violentas e quem são os criminosos e os violentos. Essa mudança de foco constitui-se em um importante passo na direção de questionar o que é, afinal, comportamento violento, desviante, delinqüente ou criminoso. Essa questão se associa, por analogia e contigüidade, a outra: o que constitui, afinal, comportamento violento ou agressivo; e, ainda, se a violência ou agressão constitui intrinsecamente um sinal de desvio, crime ou delinquência. Durkheim já havia levantado a questão e respondido que nenhum comportamento, mesmo o mais violento é, inerentemente, desviante, delinqüente ou criminoso. Essas qualificações são definidas a partir de padrões, que são determinados por grupos, comunidades ou pela sociedade como um todo. Um comportamento pode ser considerado desviante, delinqüente, criminoso, agressivo ou violento quando, por exemplo, atinge ou ofende pessoas com poder suficiente para estabelecer, através de leis, as regras sociais. A definição serve, assim, para que essas pessoas ou esses grupos se defendam do que consideram ameaças contra seus interesses. A violência passa, assim, a ser considerada no contexto das esferas de disputas de poder.

Quando um grupo consegue proscrever o comportamento de outros grupos, alertam Traub e Little (1994), aumenta o seu próprio poder, status e prestígio social. Isso leva a que, nas disputas de poder, a desqualificação de uns signifique a vitória de outros. A definição do outro como violento, agressivo, desviante, delinqüente ou criminoso torna-se um objetivo e uma ferramenta para obtenção de mais poder. Tal desqualificação do outro serve de base às atitudes preconceituosas e à marginalização, pelas sociedades, de determinados grupos, além de sustentar a idéia de que esses grupos não podem compartilhar da vida social com aqueles que estão adequados às normas. Assim marginalizados, os portadores do estigma podem, então, ser institucionalizados, sendo-lhes proposto um novo papel social, que vivem em contraposição aos papéis daqueles que deles passam a cuidar, no contexto das chamadas instituições totais. ${ }^{4}$

Expande-se a discussão teórica sobre a normatização social, desde as considerações remotas de Durkheim (1972) e, posteriormente, entre outros, de Goffman (1965) e Traub e Little (1994), para o terreno políti- 
co e econômico, focando-se a emergência do capitalismo e a exacerbação das desigualdades entre as classes sociais. Enfatiza-se aí o papel do Estado e das elites econômicas na produção da violência, do desvio, do crime e da delinquência, tanto em suas formas mais comuns como no que concerne a sua definição como meio de servir aos interesses do capital.

A análise contemporânea da violência incorpora as teorias sociológicas apresentadas acima, cujas idéias passaram a fazer parte do imaginário social e, eventualmente, da linguagem popular. Nenhuma dessas teorias é aceita, nas Ciências Sociais, como a explicação única, e nenhuma é rejeitada em sua totalidade. Todas são usadas para explicar o fenômeno da violência, às vezes utilizando-se uma delas para explicações de certas manifestações específicas, às vezes para subsidiar uma explicação mais abrangente de determinadas formas de manifestação do desvio, do crime e da agressividade. A estas análises sociológicas incorpora-se, contemporaneamente, a busca de mais explicações da violência, tanto ao nível estrutural da sociedade quanto ao nível da contextualização cultural da existência.

\section{Violência, Ética e Cultura}

Durkheim (1972) nos dá subsídios para abordar a violência numa perspectiva ética, o que implica, ainda, uma análise cultural, se aceitarmos a ética como um processo filosófico de determinar o que é o certo, diferenciando-o do errado (Singer, 1998). Definindo os valores éticos a sociedade define o que entende por virtude e vício, norma e desvio, crime, culpabilidade e inocência. E assim estabelece o que é violência contra o indivíduo ou contra um grupo, determina uma moralidade onde geralmente condena a violência, valorizando-a negativamente, contra os valores positivos que definem o bem e a virtude. Por esses motivos, entre outros, nas sociedades ocidentais contemporâneas a violência é abordada na perspectiva de sua impedição e diminuição e de seu controle, condenando-se principalmente o uso da força física e do constrangimento psíquico para obrigar alguém a agir de modo contrá- rio à natureza do seu ser. Violência, nesse caso, é a violação da integridade física e psíquica, da dignidade humana de alguém. Nesse sentido, existe violência em tudo que nos rouba a condição de sujeito, ou seja, que reduz a pessoa à condição de objeto (Chauí, 1986).

Assim, a ética ocidental situa a violência, no imaginário popular, principalmente em relação aos ataques contra a pessoa e contra os direitos do indivíduo. Por outro lado, o padrão cultural do direito, herdado do império romano, volta-se principalmente para os negócios privados. Com a ascensão do capitalismo, ampliou-se este foco do direito aos ataques contra a pessoa e contra o patrimônio. Nessa lógica capitalista explica-se porque o crime individual e às vezes roubos de menor magnitude horrorizam a população, enquanto se aceita que um Estado invada outro e mate milhões de pessoas ou se tolera que governantes e funcionários públicos e privados pratiquem corrupção com conseqüências nefastas para toda a população e prejuízos materiais de alta magnitude para a nação.

O aparato social de combate à violência envolve estruturas complexas de segurança pública, ações individualizadas de juízes e policiais, e dispositivos de controle do comportamento, inclusive localizados na área da saúde. A interpretação da violência, aplicada a essas estruturas e dispositivos, influi profundamente no estabelecimento de políticas, programas e projetos envolvidos no tratamento social que se prescreve para o fenômeno. Como nesta interpretação privilegia-se a repulsa à violência contra o indivíduo e a propriedade, o investimento maior para a intervenção passa a ser essencialmente voltado para a defesa do indivíduo e da propriedade, desconsiderando-se largamente outros tipos de violência para a qual a análise sociológica tem apontado, como a violência que se pratica a partir de grupos de interesses e aquelas perpetradas no contexto das desigualdades e sob a égide da opressão política com base na assimetria do poder econômico.

Taylor e colaboradores (1973) argumentam que a violência e o crime contra a pessoa e o patrimônio tomaram, a partir da década de 1960, características novas, apresentando-se frente à classe média dos EUA

4 São as instituições de internamento, caracterizadas por barreiras, físicas e imateriais, à relação social com o mundo externo, e por proibições à saída das pessoas ali internadas. Incluem-se nesta classificação asilos, manicômios, cadeias, reformatórios, campos de concentração, quartéis, conventos e até certos locais de moradia, como de empregados em mansões (Goffman, 20o1, p. 16-17). 
como um fenômeno preocupante por sua nova feição de brutalidade e pela sua nova qualidade de perversão social. Não que houvesse, necessariamente, mais violência, mas revelou-se perante a sociedade americana - e suas subsidiárias culturais - novas faces da crueldade e da capacidade de desrespeito do ser social por seus pares. Esse fenômeno, magistralmente capturado por Stanley Kubrik em sua obra cinematográfica Laranja Mecânica, se oferece hoje plenamente aos olhos de praticamente todas as populações de todos os países capitalistas ocidentais, inclusive o Brasil.

Do ponto de vista criminal, uma imensa tipologia se estabelece no Direito e se reflete num emaranhado de leis que são objeto da interpretação de juristas, advogados, entidades de defesa do cidadão e instituições sociais de controle do comportamento. Essa tipologia foge aos propósitos deste texto, embora alguns de seus aspectos tenham sido brevemente tratados acima, como o estabelecimento da norma, dos desvios e da delinquência, os casos a que Minayo (1994) se refere como ações fora da lei socialmente reconhecida. Resta discutir uma abordagem estrutural do comportamento violento.

\section{Violência Estrutural}

Não se pode deixar de reconhecer, como determinante do comportamento violento, a própria estrutura social. Aponta-se aí o papel simbólico das relações de poder exercidas no âmbito do funcionamento das instituições sociais, inclusive nas relações de trabalho, e as trocas inerentes ao processo social de produção e consumo de bens e serviços. As leis que regem a organização e a divisão do trabalho, bem como as relações de comércio, se originam das ideologias que configuram o sistema econômico que, por sua vez, têm influência fundamental na estrutura social. A violência responde à maneira como se trata o ser humano na sociedade e, portanto, à ideologia, ao grau de desumanização e à atribuição de importância que se dá aos valores hegemônicos e sua relação com os mandatos sociais que orientam as maneiras de se encarar a vida.

A estrutura social capitalista, sob os auspícios da ética neoliberal, no mundo contemporâneo, é vista por muitos autores como essencialmente fomentadora de desigualdades, de assimetrias de poder político e econômico e, conseqüentemente, de opressão (Bauman,
1999; Morin, 1999; Santos, 1996). Essa ética do pósmercado, como se refere Rifkin (1995), privilegia a exploração do trabalho, minando a dignidade humana e facilitando a erosão da auto-estima e da constituição sadia da subjetividade. A estrutura ideológica hegemônica na idade contemporânea, vista desta forma, viola, violenta e fomenta a violência em níveis interpessoal, inter e intragrupal e institucional, favorecendo o aparecimento de sofrimento material, biopsíquico e social. Minayo (1994) aponta que há diferentes formas de resposta violenta à violência estrutural por parte dos grupos, classes, nações e indivíduos oprimidos. A autora as denomina violência de resistência.

Na mesma linha de raciocínio, mas a partir da análise de questões ligadas ao totalitarismo e ao autoritarismo, Arendt (1994) cita a violência autoritária, que se manifesta principalmente como forma de dominação e afirmação de poder. Fanon (1979) refere-se à violência libertária como a busca de libertação por parte de populações oprimidas no contexto de processos de colonização. Essa visão é compartilhada por Carmichael e Hamilton (1967), em sua análise do racismo nos EUA, e por Sorel (1992) no da luta de classes. Manifestações dessa forma de violência reativa à opressão são, na visão de Sorel (1992), conduzidas no âmbito dos movimentos sociais, inclusive as greves.

\section{De Volta à Saúde Coletiva}

Diversas outras abordagens no sentido de estabelecer uma classificação da violência poderão ser encontradas na vasta literatura existente sobre o assunto. Este texto se limitou a algumas definições e classificações que emanam do pensamento sociológico clássico, juntamente com algumas considerações mais recentes sobre as relações sociais contemporâneas, no intuito de trazer subsídios para a formulação de ações que possam influir positivamente sobre a qualidade de vida e a saúde das populações. Nesse sentido, visa essencialmente trazer, ao profissional da Saúde Coletiva, perspectivas disciplinares pouco exploradas nos currículos da área da saúde, o que percebemos como um vácuo em relação a um tema importante na prática diária do profissional de saúde.

É comum, em nosso campo, uma tendência a reduzir nosso pensamento à abordagem clínica, o que sig- 
nifica, muitas vezes, ajustar os fenômenos sociais e existenciais a determinadas categorias patológicas e nosológicas, com as quais nos sentimos mais à vontade. Essa prática pode aliviar nosso anseio por explicações que nos sejam familiares, mas é freqüentemente ilusória e nos nega visões mais acuradas e muitas vezes mais precisas. A tendência a medicalizar a vida é um perigo constante na área da saúde e pode contribuir negativamente para o planejamento de intervenções sobre grupos e populações que podem, através de seus comportamentos, estar nos comunicando fatos para os quais, sem um referencial diferenciado, tornam-se mais difíceis de perceber.

Buscamos, assim, contribuir para uma percepção mais acurada do comportamento agressivo e violento, a partir de uma ótica diferente dos modelos de nossas formações como profissionais de saúde. Ao enfatizar a complexidade do tema, buscamos catalisar um grau maior de diálogo entre disciplinas das ciências sociais e humanas e da saúde, ampliando as possibilidades de compreender e explicar o fenômeno da violência. Nesse sentido, esperamos que se aprofundem cada vez mais, no campo da Saúde Coletiva, discussões deste teor, que se fazem cada vez mais necessárias para instrumentalizar decisões demandadas no âmbito da promoção da saúde, da reabilitação de agravos, e do bem-estar da coletividade.

\section{Referências}

ABBAGNANO, N. Dicionário de filosofia. 2. ed. São Paulo: Martins Fontes, 2000.

ADLER, P. A.; ADLER, P. Constructions of deviance: social power, context, and interaction. Belmont: Wadsworth, 1994 .

ARENDT, H. Sobre a violência. Rio de Janeiro: Dumará, 1994.

BAUMAN, Z. Modernidade e ambivalência. Rio de Janeiro: J. Zahar, 1999.

CARMICHAEL, S.; HAMILTON, C. Black power: the politics of liberation in America. New York: Vintage Books, 1967.
CDC - Centers for Disease Control and Preventidon. Department of Health and Human Services. Youth violence. Disponível em: <http://www.cdc.gov/ncipc/ factsheets/yvfacts.htm>. Acesso em: 11 abr. 2008.

CHAUÍ, M. Conformismo e resistência: aspectos da cultura popular no Brasil. São Paulo: Brasiliense, 1986.

DURKHEIM, E. Selected writings. Londres: Cambridge University, 1972.

FANON, F. Os condenados da terra. Rio de Janeiro: Civilização Brasileira, 1979.

FREIRE, P.; FAUNDEZ, A. Learning to question. New York: Continuum, 1989.

GOFFMAN, E. Stigma: notes on the management of spoiled identity. Englewood Cliffs: Prentice-Hall, 1965.

GOFFMAN, E. Manicômios, prisões e conventos. 7. ed. São Paulo: Perspectiva, 2001 (orig. 1961).

KAPLAN, H. I.; SADOCK, B. J.; GREBB, J. A. Compêndio de psiquiatria: ciências comportamentais e psiquiatria clínica. 7. ed. Porto Alegre: Artes Médicas, 1997.

MINAYO, M. C. de S. A violência social sob a perspectiva da saúde pública. Cadernos de Saúde Pública, Rio de Janeiro, v. 10, p. 7-18, 1994.

Suplemento 1.

MINAYO, M. C. de S.; SOUZA, E. R. de. Violência sob o olhar da saúde: a infrapolítica da contemporaneidade brasileira. Rio de Janeiro: Fiocruz, 2003.

MORIN, E. A inteligência da complexidade. 2. ed. São Paulo: Peirópolis, 2000.

NEW Lexicon Webster's dictionary of the English language: encyclopedic edition. New York: Lexicon, 1989.

NOGUEIRA, J. C. O inconsciente e a linguagem na compreensão do homem. São Paulo: Cortez \& Moraes, 1978.

RIFKIN, J. The end of work: the decline of the global labor force and the dawn of the post-market era. New York: G. P. Putnam's Sons, 1995. 
RUBINGTON, E.; WEINBERG, M. S. Deviance, the interactionist perspective. New York: MacMillan, 1968.

SANTOS, B. de S. Pelas mãos de Alice: o social e o político na pós-modernidade. 2. ed. São Paulo: Cortez, 1996.

SINGER, P. Ética prática. 2. ed. Rio de Janeiro: Martins Fontes, 1998.
SOREL, G. Reflexões sobre a violência. São Paulo: Martins Fontes, 1992.

TAYLOR, I.; WALTON, P.; YOUNG, J. The new criminology: for a social theory of deviance. New York: Harper \& Row, 1973.

TRAUB, S. H.; LITTLE, C. B. Theories of deviance. 4. ed. Itasca: F. A. Peacock, 1994.

WITTGENSTEIN, I. Investigações filosóficas. São Paulo: Abril Cultural, 1979. 